\title{
An internally consistent framework for the global and regional chemical variability of parental arc magmas
}

\author{
StePhen J. TURNER ${ }^{1}$ CHARles H. LANGMUIR ${ }^{2}$
}

${ }^{1}$ University of Massachusetts Amherst Department of Geosciences

${ }^{2}$ Harvard University Department of Earth and Planetary Sciences

Variations in arc magma compositions which persist to high $\mathrm{Mg \#}$ require a mantle origin. High $\mathrm{MgO}$ samples from large arc stratovolcanoes exhibit global and regional correlations between many diagnostic compositional and geophysical parameters, though on a regional scale other key trace element and isotope ratios have no obvious relationship to physical observations. Here we interpret arc geochemistry under the lens of recent work in experimental petrology and a systematic framework for geochemical modeling. Key findings include: 1) Ubiquitous high $\mathrm{Sr} / \mathrm{Nd}$ but low ${ }^{87} \mathrm{Sr} /{ }^{86} \mathrm{Sr}$ values must originate from the ocean crust. This signal is not consistent with experimental analogs for "aqueous fluids" or "mélange diapirs," while melts of basaltic ocean crust mixed with typical mantle compositions match well. The mixed mantle source requires $5-10 \%$ ocean crust melt, globally 2) Canonical tracers of "aqueous fluids" are better explained by variations in the influence of variable subducting sediment lithologies and ocean crust melts 3) Trace element and isotopic data require ambient mantle compositions spanning from more depleted than any MORB to as enriched as OIB mantle 4) Average extents of melting vary globally by a factor of $\sim 4$ and are lowest in continental arcs. A geochemical model motivated by these observations and consistent with experimental data and thermo-mechanical models reproduces global trends in arc geochemistry. This same model provides internally consistent solutions to outstanding questions about regional arc geochemical variations from Mexico, Tonga, and the Marianas. 